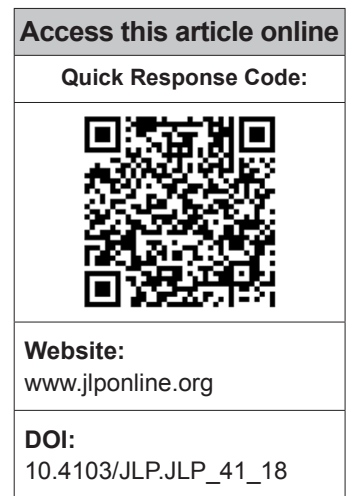

Departments of Internal Medicine, ${ }^{3}$ Biochemistry, ${ }^{4}$ Pathology and ${ }^{5}$ Biostatistics, Faculty of Medicine, Bulent Ecevit

University, ${ }^{2}$ Department of Internal Medicine,

Division of Endocrinology and Metabolism, Faculty of Medicine, Bulent Ecevit

University, Zonguldak,

${ }^{1}$ Department of Internal

Medicine, Division of

Endocrinology and

Metabolism, Evliya Çelebi

Training and Research

Hospital, Dumlupinar University, Kütahya, Turkey

Address for correspondence:

Dr. Fatih Kuzu,

Department of Internal

Medicine, Division of

Endocrinology and Metabolism, Evliya Çelebi

Training and Research Hospital, Dumlupinar

University, Kütahya, Turkey.

E-mail: drfkuzu@hotmail.

Submission: 26-03-2018 Accepted: 22-11-2018

\title{
Correlation of vascular endothelial growth factor and vascular endothelial growth factor receptor-1 levels in serum and thyroid nodules with histopathological and radiological variables
}

\author{
Gurkan Haytaoglu, Fatih Kuzuㅁ, Dilek Arpaci ${ }^{2}$, Ayfer Altas, Murat Can ${ }^{3}$, Figen Barut ${ }^{4}$, \\ Furuzan Kokturk ${ }^{5}$, Sevil Uygun Ilikhan, Taner Bayraktaroglu²
}

Abstract:

BACKGROUND/AIM: Vascular endothelial growth factor (VEGF) is a major cytokine in angiogenesis and has a role on aggressivity of various tumors. The expression of VEGF has been shown to increase in differential thyroid cancer. The aim of the study was to evaluate serum and intranodular VEGF (nVEGF) and VEGF receptor-1 (VEGFR-1) levels in patients with thyroid nodules and their relevance to ultrasonographic and pathological results.

MATERIALS AND METHODS: A total of eighty patients were included in the study. Thyroid fine-needle aspiration biopsies were performed, and the levels of serum and nVEGF and VEGFR-1 were measured. Any possible correlations between serum and nVEGF, VEGFR-1, and biochemical/radiological variables were investigated.

RESULTS: There were no significant differences between serum VEGF (sVEGF), nVEGF, sVEGFR-1, nVEGFR-1 levels, number of nodules, size of nodules, and benign and malignant ultrasonographic features. sVEGF and nVEGF were higher in malignant or suspicious nodules than that in benign nodules, but did not reach statistical significance $(P>0.05)$. sVEGFR-1 and nVEGFR-1 levels were higher in hyperthyroid patients than that in euthyroid patients $(P<0.05$ and $P=0.003$, respectively). nVEGFR-1 level was higher in hypothyroid patients than that in euthyroid patients $(P=0.016)$. sVEGF level was found to be higher in hyperactive nodules than that in others. Both sVEGFR-1 $(P=0.008)$ and nVEGF levels $(P=0.01)$ significantly increased with increasing age. nVEGFR-1 decreased with increasing body mass index (BMI) $(P=0.004)$.

CONCLUSIONS: Our study showed the relationships of sVEGF, nVEGF, sVEGFR-1, and nVEGFR-1 levels with age, gender, BMI, and hyperthyroidism. To determine the role of VEGF/VEGFR-1 in thyroid nodules, further studies are required with a large number of patients.

Key words:

Malignancy, nodule, thyroid

\section{Introduction}

The incidence of thyroid nodules has increased by approximately $19 \%-67 \%$,

This is an open access journal, and articles are distributed under the terms of the Creative Commons Attribution-NonCommercial-ShareAlike 4.0 License, which allows others to remix, tweak, and build upon the work non-commercially, as long as appropriate credit is given and the new creations are licensed under the identical terms.

For reprints contact: reprints@medknow.com and the incidence of malignancy in thyroid nodules has increased sharply and reached $5 \%-15 \%$ because of the recent use of high-resolution ultrasound. Fine-needle aspiration biopsy (FNAB) is the most

How to cite this article: Haytaoglu G, Kuzu F, Arpaci D, Altas A, Can M, Barut F, et al. Correlation of vascular endothelial growth factor and vascular endothelial growth factor receptor-1 levels in serum and thyroid nodules with histopathological and radiological variables. J Lab Physicians 2019;11:51-7. 
accurate and cost-effective method for evaluating thyroid nodules. ${ }^{[1]}$ However, there are some disadvantages of FNAB; it is an invasive procedure that depends on the technical performance of the operators. False-negative rates can be $1 \%-6 \%$ even in adequate examples, and the experience of FNAB, especially in nodules $>4 \mathrm{~cm}$ or $<1 \mathrm{~cm}$, is important. ${ }^{[2,3]}$ Because of these reasons, some genetic markers (BRAF, Ras, RET/PTC, etc.) or protein markers (galectin-3, HBME-1, cytokeratin-19, etc.) have been used to help give a more accurate preoperative diagnosis in thyroid nodules. ${ }^{[4,5]}$

The most widely accepted hypothesis for the formation of nodules in the thyroid is the stimulation of the growth of thyroid cells by thyroid-stimulating hormone (TSH). In addition to TSH, some growth factors such as immunoglobulins and cytokines (insulin-like growth factors, epidermal growth factor [transforming growth factor- $\alpha$ ], transforming growth factor-beta, platelet-derived growth factor [PDGF], fibroblast growth factor, nerve growth factor, and vascular endothelial growth factor [VEGF]) are involved in the regulation of cell proliferation and cellular differentiation in thyroid cells. ${ }^{[6]}$

VEGF is a member of the PDGF family, and it is specific for endothelial cells. VEGF is placed on the short arm of chromosome 6 (6p12), and its molecular weight is $45 \mathrm{kDa}$. It plays a role in several pathological disorders, including tumor growth and the spread of physiological processes in the body. ${ }^{[6]}$ VEGF is stored in the $\alpha$-granules of platelets, and an important source of VEGF is megakaryocytes. VEGF is also a glycoprotein secreted from different cells in the body and from tumor cells. ${ }^{[7,8]}$

VEGF is a potent mitogen for vascular endothelial cells, but it has no mitogenic activity in other cell types. Selective mitogenic effects of VEGF on endothelial cells induce angiogenesis as well as morphogenesis and chemotaxis. ${ }^{[6]}$

There are six members of the VEGF family, namely VEGF-A, VEGF-B, VEGF-C, VEGF-D, VEGF-E, and placental growth factor. There are three receptors on endothelial cells for binding with high affinity; VEGF receptor-1 (VEGFR-1) and VEGFR-2 lie on the vascular endothelium and VEGFR-3 lies on lymphatic vessels. ${ }^{[9]}$

There are few reports in the literature about VEGFR/VEGFR-1 levels in thyroid nodule patients. Our study was designed to determine the serum and intranodular levels of VEGF and VEGFR-1 in thyroid nodule patients and to evaluate the correlation between clinical, laboratory, aspiration cytology, and histopathological findings.

\section{Materials and Methods}

\section{Study design}

This prospective study included eighty patients between the ages of 26 and 82 years with nodular goiter who were admitted to the endocrinology department of a tertiary care center between March 2012 and May 2013. This study was approved by the local Institutional Review Board (date: 28.03.2012/Number 2012.07), and written informed consent was obtained from every patient included in this trial.

\section{Outcome parameters}

The study patients were evaluated for initial physical examination, routine biochemical tests, and anthropometric measurements. Antecubital venous blood samples were taken in the morning after $12 \mathrm{~h}$ of fasting and evaluated for complete blood count, free triiodothyronine (FT3), free thyroxine (FT4), TSH, and sedimentation. Thyroid function tests (TSH, FT3, and FT4) were measured by direct chemiluminescence method (Advia Centaur XP, Siemens, Dublin, Ireland). Normal limits were as follows: FT3: $1.8-4.7 \mathrm{pg} / \mathrm{ml}$, FT4: $0.8-2.6 \mathrm{pg} / \mathrm{ml}$, and TSH: $0.4-6 \mu \mathrm{IU} / \mathrm{ml}$.

A thyroid scintigraphy scan of the patients was performed by giving pertechnetate ( $5 \mathrm{mCiTc})$. Thyroid ultrasounds of patients enrolled in the study prior to FNAB were performed using a high-resolution ultrasound device with a $7.5 \mathrm{MHz}$ probe. The following ultrasonographic features were evaluated and recorded: size with three dimensions, nodular structure (pure solid, cystic, and mixed), echogenicity (hypoechoic, isoechoic, and hyperechoic), nodular contour (smooth and irregular), the presence of peripheral halo, and the presence and type of calcification (microcalcification and macrocalcification). We did not perform power Doppler for patients.

Initially vein punction and then fine needle aspiration (FNA) were performed to measure VEGF. Blood samples were centrifuged for $5 \mathrm{~min}$ at $5000 \mathrm{rpm}$. Ultrasound-guided FNAB was performed using a 22G needle and 10 -cc syringe. Thyroid FNA materials were centrifuged at $2000 \mathrm{rpm}$ for $5 \mathrm{~min}$. FNAB samples were fixed in alcohol and sent to the pathology department. VEGF and VEGFR-1 levels (ng/ $\mathrm{mL}$ ) in serum and within nodules received from aspiration materials were studied using a commercially available Platinum Human VEGF-A ELISA kit (eBioscience, Vienna, Austria). The assay range was $0-1000 \mathrm{pg} / \mathrm{ml}$.

Serum (sVEGFR-1) and intranodular VEGFR-1 (nVEGFR-1) levels were determined using a commercially available Human sVEGFR-R1 Platinum ELISA kit (eBioscience, Vienna, Austria). The assay range was $0-10 \mathrm{ng} / \mathrm{ml}$. The reference range was $0.42 \mathrm{ng} / \mathrm{ml}$. 


\section{Statistical analysis}

Statistical evaluation was performed using SPSS program version 18.0 (SPSS Inc., Chicago, IL, USA). The normality of the distribution of quantitative variables was analyzed with the Shapiro-Wilk test. Descriptive statistics for numerical variables were defined as the mean \pm standard deviation and median (minimum-maximum) and as number and percentage for the categorical data. Differences between the groups in terms of categorical variables were examined by the Chi-square test. Quantitative variables were compared in the two groups via the Mann-Whitney U-test, and Kruskal-Wallis variance analysis was used for the comparison of the three groups. Pair-wise comparison of subgroups in the Kruskal-Wallis variance analysis was performed with a Bonferroni-corrected Mann-Whitney U-test. The relationship between two numerical variables was examined using Spearman's correlation analysis. Results were evaluated within the $95 \%$ confidence interval, and $\mathrm{P}<0.05$ was considered statistically significant.

\section{Results}

A total of eighty patients were enrolled in this study; $62(77.5 \%)$ cases were women and $18(22.5 \%)$ were men, and the mean age was $54.1 \pm 13.3$ years. The average body mass index (BMI) was $27.6 \pm 4.2 \mathrm{~kg} / \mathrm{m}^{2}$.

According to thyroid status, $56.3 \%(n=45)$ of the patients were euthyroid, $33.7 \%(n=27)$ of the patients had hyperthyroidism, and $10 \%(n=8)$ of the patients had hypothyroidism. Results of laboratory tests of patients with hyper- and hypo-thyroidism are shown in Table 1. Fourteen patients had Graves' disease, 6 had Hashimoto's thyroiditis, and 13 had toxic nodular goiter. Six patients were being treated with levothyroxine and 21 patients with antithyroid drugs. The median TSH, serum VEGF (sVEGF), nVEGF, sVEGFR-1, and nVEGFR1-1 were $0.84(0.004-64.3) \mu \mathrm{IU} / \mathrm{ml}, 65.2 \mathrm{pg} / \mathrm{mL}$, $20.22 \mathrm{pg} / \mathrm{mL}, 0.9 \mathrm{ng} / \mathrm{ml}$, and $0.09 \mathrm{ng} / \mathrm{ml}$, respectively. There were no statistically significant differences between sVEGF, nVEGF, and nVEGFR-1 levels based on gender $(P>0.005)$. However, sVEGFR-1 in men was higher than that in women $(P=0.045)$ [Table 2].

Although nVEGFR-1 was significantly higher in normal BMI patients compared to obese patients $(P=0.02)$ [Table 2], there were no differences among sVEGF, sVEGFR-1, and nVEGFR-1 levels.

Table 1: Results of laboratory tests of patients with hyper- and hypo-thyroidism

\begin{tabular}{lccc}
\hline Thyroid status & TSH $(\mu \mathrm{lU} / \mathrm{ml})$ & FT3 $(\mathrm{pg} / \mathrm{ml})$ & FT4 $(\mathrm{pg} / \mathrm{ml})$ \\
\hline Euthyroidism & $1.48 \pm 1.09$ & $3.83 \pm 0.64$ & $1.05 \pm 0.23$ \\
Hyperthyroidism & $0.11 \pm 0.10$ & $4.38 \pm 1.17$ & $1.27 \pm 0.44$ \\
Hypothyroidism & $7.94 \pm 5.50$ & $3.96 \pm 0.61$ & $0.88 \pm 0.24$ \\
\hline
\end{tabular}

$\mathrm{TSH}=$ Thyroid-stimulating hormone, FT3 = Free triiodothyronine, FT4 = Free thyroxine
There were no significant differences in sVEGF,nVEGFR-1, sVEGFR-1, and nVEGFR-1 levels $(P>0.05)$ when the patients were subgrouped according to age (younger than 45 years and older than 45 years old), number of nodules (single and multinodular), or benign and malignant ultrasonographic features (large nodules $>4 \mathrm{~cm}$, microcalcifications, intranodular hypervascularity, irregular border, hypoechoic structure, incomplete thick halo, and regional lymphadenopathy) [Table 2].

When we grouped patients according to thyroid status, sVEGFR-1 and nVEGFR-1 levels were higher in hyperthyroid patients than that in euthyroid patients $(P<0.05$ and $P=0.003$, respectively). In addition, the nVEGFR-1 level was higher in hypothyroid patients than that in euthyroid patients $(P=0.016)$ [Table 2].

There were no significant differences in sVEGFR-1, nVEGFR-1, or nVEGF levels between the groups according to scintigraphic sign. However, sVEGF was found to be higher in hyperactive nodules [Table 2].

sVEGF, sVEGFR-1, nVEGF, and nVEGFR-1 levels did not significantly differ according to the thyroid nodule size $(P>0.05)$ [Table 2].

Cytopathology results were divided according to Bethesda system. Seventy-three patients were in Bethesda 2, and three patients had undetermined significance (atypia or follicular lesion of undetermined significance (Bethesda III). Three patients had suspicious follicular neoplasm (Bethesda IV), and one patient had poorly differentiated thyroid cancer (Bethesda VI). There were no significant differences in sVEGF, sVEGFR-1, nVEGF, or nVEGFR-1 levels in groups according to the Bethesda categories $(P>0.05)$ [Table 3]. Histopathological results of the three patients who underwent surgery were as follows: one of them had papillary microcarcinoma, another one had follicular variant of papillary carcinoma $(>1 \mathrm{~cm})$, and the last one had follicular thyroid cancer $(>1 \mathrm{~cm})$.

In total, $23.75 \%$ of the cases (14) underwent surgery, $21.4 \%$ (3) had malignant histopathology, $57.2 \%$ (8) had nodular hyperplasia, and $21.4 \%$ (3) had follicular adenoma [Table 4]. Histopathological results of 14 patients are shown in Table 5. There was a trend toward increase for sVEGF, sVEGFR-1, nVEGF, or nVEGFR-1 levels in malignant nodules, but they did not reach statistical differences $(P>0.05)$.

Both sVEGFR-1 $(r=0.29 ; P=0.008)$ and nVEGF levels $(r=0.29 ; P=0.01)$ significantly increased with increasing age. nVEGFR-1 decreased with increasing BMI $(r=-0.32 ; P=0.004)$. There was no relationship 
between nodule size and sVEGF, nVEGF, sVEGFR-1, and nVEGFR-1 levels $(P>0.05)$. There was a correlation between both sVEGF/nVEGF and sVEGFR-1 and nVEGFR1-1 $(r=0.47, P=0.001 ; r=0.31, P=0.006)$ [Table 6 and Figures 1-3].

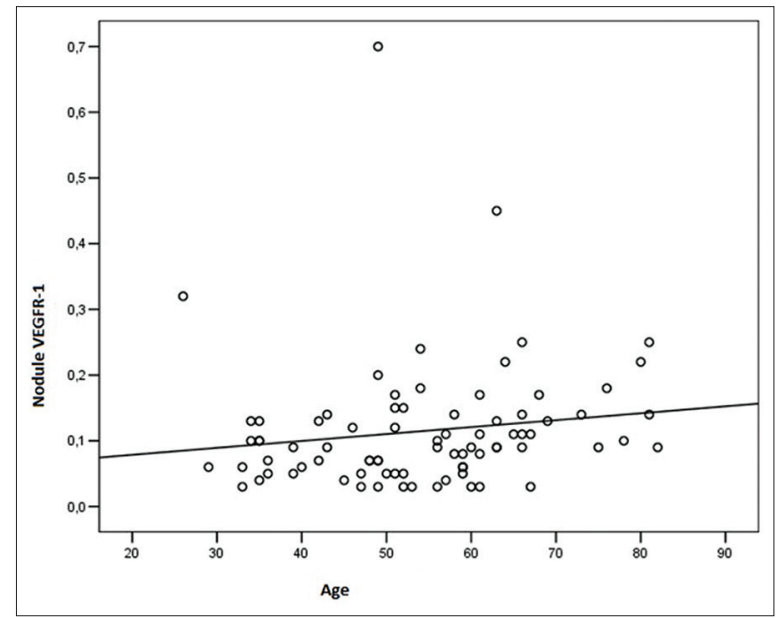

Figure 1: Correlation between nodule vascular endothelial growth factor receptor-1 and age

\section{Discussion}

Angiogenesis (neovascularization) is necessary for the progression of tumors. ${ }^{[10]}$ Angiogenesis begins

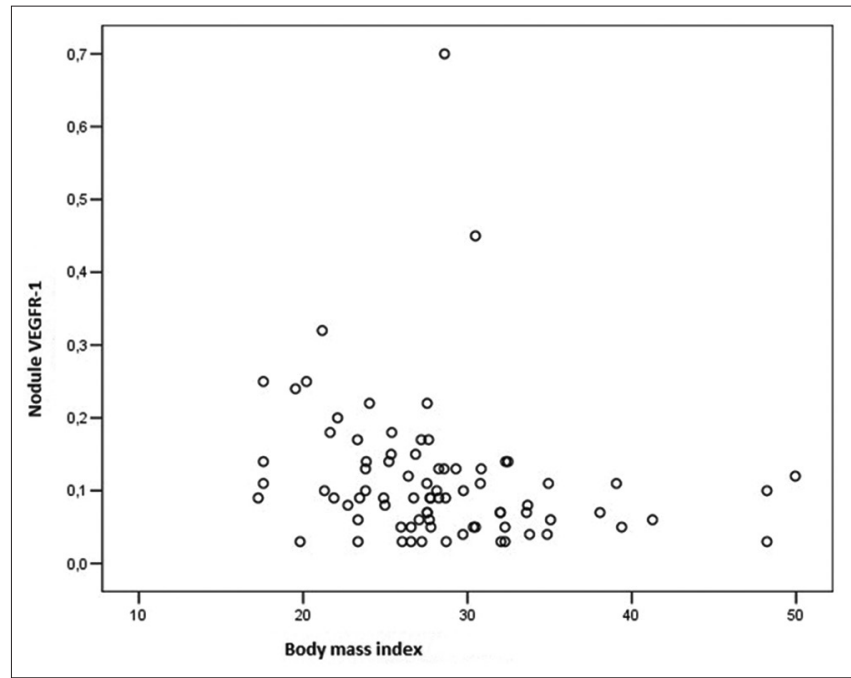

Figure 2: Correlation between nodule vascular endothelial growth factor receptor-1 and body mass index

Table 2: Demographic, clinical, and laboratory features in thyroid nodules

\begin{tabular}{|c|c|c|c|c|}
\hline \multirow[t]{2}{*}{ Feature } & \multicolumn{2}{|c|}{ VEGF (pg/ml) } & \multicolumn{2}{|c|}{ VEGFR-1 (ng/ml) } \\
\hline & Serum & Intranodular & Serum & Intranodular \\
\hline \multicolumn{5}{|l|}{ Age (year) } \\
\hline$<45(n=19)$ & $69.3 \pm 29.8$ & $26.28(7.9-63.1)$ & $0.07(0.03-0.18)$ & $0.09(0.03-0.32)$ \\
\hline$>45(n=61)$ & $63.9 \pm 35.9$ & $19.7(7.1-47.4)$ & $0.1(0.03-0.38)$ & $0.09(0.06-0.7)$ \\
\hline$P$ & 0.312 & 0.074 & 0.233 & 0.374 \\
\hline \multicolumn{5}{|l|}{ Number of nodules $(n=80)$} \\
\hline Single $(n=13)$ & $58.9 \pm 38.23$ & $26.1 \pm 12.44$ & $0.09(0.03-0.18)$ & $0.09(0.03-0.32)$ \\
\hline Multinodule $(n=67)$ & $66.45 \pm 33.87$ & $21.85 \pm 12.63$ & $0.09(0.03-0.38)$ & $0.1(0.03-0.7)$ \\
\hline$P$ & 0.328 & 0.733 & 0.203 & 0.456 \\
\hline \multicolumn{5}{|l|}{ USG feature } \\
\hline Benign sonography $(n=62)$ & $66.1 \pm 34.46$ & $22.6 \pm 12.65$ & $0.09(0.03-0.38)$ & $0.09(0.03-0.7)$ \\
\hline Sonography suspicious of malignancy $(n=18)$ & $58.35 \pm 35.88$ & $22.11 \pm 13$ & $0.09(0.06-0.15)$ & $0.14(0.05-0.25)$ \\
\hline$P$ & 0.451 & 0.458 & 0.976 & 0.197 \\
\hline \multicolumn{5}{|l|}{ Thyroid scintigraphy } \\
\hline Hypoactive $(n=36)$ & $56(11-142)$ & $21 \pm 13.5$ & $0.09(0.03-0.19)$ & $0.08(0.03-0.7)$ \\
\hline Hyperactive $(n=13)$ & $84(22-132)$ & $26 \pm 12$ & $0.11(0.03-0.18)$ & $0.09(0.07-0.25)$ \\
\hline$P$ & $0.024^{*}$ & 0.163 & 0.093 & 0.301 \\
\hline \multicolumn{5}{|l|}{ BMI } \\
\hline Normal $(n=55)$ & $59(11-169)$ & $20.2(7.1-48.9)$ & $0.09(0.03-0.32)$ & $0.1(0.03-0.7)$ \\
\hline Obese $(n=25)$ & $58(15-142)$ & $19.7(7.9-63.1)$ & $0.09(0.03-0.19)$ & $0.07(0.03-0.45)$ \\
\hline$P$ & 0.934 & 0.607 & 0.501 & $0.02^{*}$ \\
\hline \multicolumn{5}{|l|}{ TSH } \\
\hline$<0.4(n=27)$ hyperthyroidism & $53.3(11.8-138.7)$ & $20.6(7.9-45.4)$ & $0.11(0.03-0.38)$ & $0.11(0.03-0.25)$ \\
\hline $0.4-4(n=45)$ euthyroid & $59.9(12.6-159.6)$ & $18.9(7.1-63.1)$ & $0.07(0.03-0.19)$ & $0.07(0.03-0.45)$ \\
\hline$>4(n=8)$ hypothyroidism & $77.6(14.3-169)$ & $23.2(7.9-39.7)$ & $0.1(0.03-0.15)$ & $0.14(0.03-0.7)$ \\
\hline$P$ & 0.8 & 0.923 & $0.003^{*}$ & $0.016^{*}$ \\
\hline \multicolumn{5}{|l|}{ Nodule size } \\
\hline$<10 \mathrm{~mm}(n=26)$ & $59(11.8-142)$ & $20.2(7.1-63.1)$ & $0.09(0.03-0.38)$ & $0.09(0.03-0.7)$ \\
\hline 10 and upper than $10 \mathrm{~mm}$ & $55(22-169)$ & $20.24(7.9-41.3)$ & $0.1(0.06-0.19)$ & $0.13(0.03-0.25)$ \\
\hline$P$ & 0.891 & 0.552 & 0.274 & 0.388 \\
\hline
\end{tabular}

VEGF = Vascular endothelial growth factor, $\mathrm{TSH}=$ Thyroid-stimulating hormone, BMI = Body mass index, USG = Ultrasonographic 
Table 3: Serum and intranodular vascular endothelial growth factor and vascular endothelial growth factor receptor-1 levels according to the Bethesda categories

\begin{tabular}{lcccc}
\hline FNAB & \multicolumn{2}{c}{ VEGF } & \multicolumn{2}{c}{ VEGFR-1 } \\
\cline { 2 - 5 } & Serum & Intranodular & Serum & Intranodular \\
\hline Bethesda 2 $(n=73)$ & $56.9(11.8-169)$ & $39.1(33.7-49.8)$ & $0.09(0.03-0.33)$ & $0.09(0.03-0.7)$ \\
Bethesda 3 $(n=3)$ & $82.66(74.4-92.7)$ & $15.63(7.9-31)$ & $0.12(0.11-0.14)$ & $0.09(0.03-0.14)$ \\
Bethesda 4 $(n=3)$ & $38.96(14.3-70.3)$ & $22.03(11.2-39.4)$ & $0.13(0.08-0.17)$ & $0.14(0.13-0.17)$ \\
Bethesda 6 $(n=1)$ & 159.6 & 41.3 & 0.09 & 0.09 \\
\hline
\end{tabular}

VEGF = Vascular endothelial growth factor

Table 4: Laboratory results according to the cytological results

\begin{tabular}{lcccc}
\hline FNAB & \multicolumn{2}{c}{ VEGF } & \multicolumn{2}{c}{ VEGFR-1 } \\
\cline { 2 - 5 } & Serum & Intranodular & Serum & Intranodular \\
\hline Benign $(n=73)$ & $56.9(11.8-169)$ & $39.1(33.7-49.8)$ & $0.09(0.03-0.33)$ & $0.09(0.03-0.7)$ \\
Suspicious and malignant $(n=7)$ & $74.4(14.3-160)$ & $20.2(7-63)$ & $0.13(0.08-0.11)$ & $0.13(0.03-0.17)$ \\
$P$ & 0.512 & 0.851 & 0.051 & 0.290 \\
\hline
\end{tabular}

$\overline{\mathrm{VEGF}}=$ Vascular endothelial growth factor, FNAB = Fine-needle aspiration biopsy

Table 5: Laboratory results according to the histopathological results

\begin{tabular}{lcccc}
\hline \multirow{2}{*}{ Histopathology } & \multicolumn{2}{c}{ VEGF } & \multicolumn{2}{c}{ VEGFR1 } \\
\cline { 2 - 4 } & Serum & Nodule & Serum & Nodule \\
\hline Benign $(n=11)$ & $61.20 \pm 36.63$ & $18.57 \pm 16.45$ & $0.098 \pm 0.056$ & $0.119 \pm 0.104$ \\
Malign $(n=3)$ & $87.40 \pm 65.35$ & $30.63 \pm 16.85$ & $0.095 \pm 0.038$ & $0.084 \pm 0.052$ \\
$P$ & 0.586 & 0.185 & 0.639 & 0.307 \\
\hline
\end{tabular}

VEGF = Vascular endothelial growth factor

with local destruction of capillaries surrounding the basement membrane followed by invasion of the surrounding stroma. ${ }^{[11]}$ The most powerful external stimulus for the expression of angiogenic factors is hypoxia. ${ }^{[12]}$ VEGF is the most potent angiogenic factor; it increases the permeability of endothelial cells and stimulates the accumulation of fluid by paracrine effects. VEGF increases endothelial cell proliferation, stimulates cell migration, and inhibits apoptosis. VEGF is a glycoprotein; it is $34-42 \mathrm{kDa}$ by weight, and its expression has been shown in various cancer

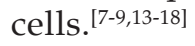

Angiogenesis plays an important role in the proliferation of both thyroid follicular cells and endothelial cells. ${ }^{[19]}$ The VEGF level was found to be high in serum and intrathyroidal vascular area both in Hashimoto's and Graves' diseases. Thyroid tumors have more vascular structures compared to the normal thyroid. VEGF and VEGFR levels are increased in Graves' disease due to increased synthesis by thyrocytes via paracrine effects. ${ }^{[20-24]}$ Similarly, in our study, both sVEGFR-1 and nVEGFR-1 were higher in hyperthyroid patients compared to euthyroid patients $(P=0.003$ and $P=0.003$, respectively). In addition, we found that the nVEGFR-1 level was higher in hypothyroid patients compared to euthyroid patients $(P=0.016)$. Hataya et al. have reported a case with subclinical hypothyroidism and elevated sVEGF. ${ }^{[25]}$

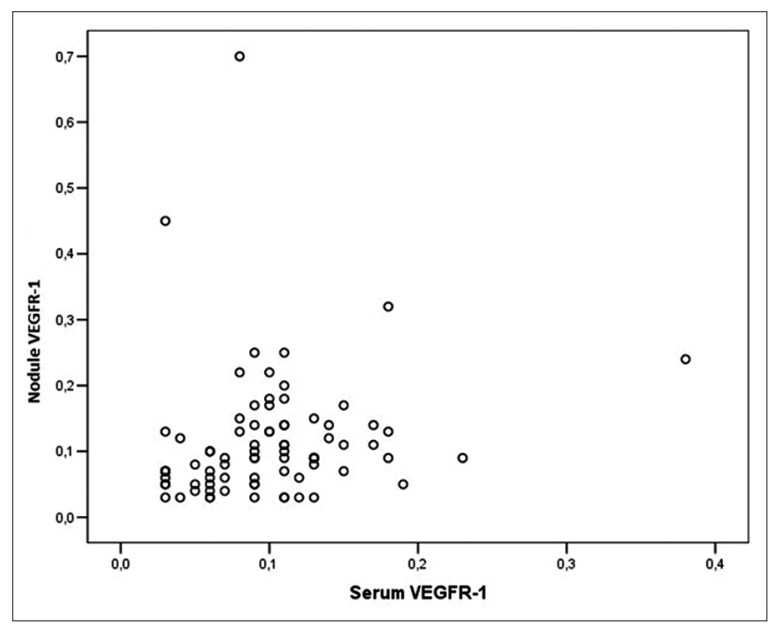

Figure 3: Correlation between nodule vascular endothelial growth factor receptor-1 and serum vascular endothelial growth factor receptor-1

Zhao et al. found that the plasma VEGF level in hyperthyroid patients was lower than that in a control group. ${ }^{[2]}$ However, another study found a different result, with no differences between thyroid status groups. ${ }^{[27]}$ Similar to the latter report, we did not find any differences between sVEGF and nVEGF levels according to thyroid status. However, we found that the sVEGF level was higher in hyperactive nodules than in normo-hypoactive nodules.

Positive correlations between VEGF in cyst fluid and the recurrence and growth of cystic thyroid nodules have been reported. ${ }^{[16-18]}$ These studies showed a correlation between the VEGF concentration and thyroid volume but did not find a correlation between VEGF and cyst volume. In our study, we did not find any correlation between nodule size and sVEGF, nVEGF, sVEGFR-1, or nVEGFR-1 levels. In contrast to our results, other studies have reported that VEGF expression correlates with tumor size. ${ }^{[28]}$ 
Table 6: Correlation between laboratory parameters and age, body mass index, and nodule size

\begin{tabular}{|c|c|c|c|c|}
\hline \multirow[t]{2}{*}{ Feature } & \multicolumn{2}{|c|}{$\begin{array}{c}\text { VEGF } \\
r ; P\end{array}$} & \multicolumn{2}{|c|}{$\begin{array}{c}\text { VEGFR-1 } \\
r ; P\end{array}$} \\
\hline & Serum & Intranodular & Serum & Intranodular VEGFR-1 \\
\hline Age & $-0.08 ; 0.499$ & $-0.16 ; 0.147$ & $0.29 ; 0.008^{*}$ & $0.29 ; 0.01^{*}$ \\
\hline BMI & $-0.04 ; 0.747$ & $-0.09 ; 0.455$ & $-0.06 ; 0.618$ & $-0.32 ; 0.004^{*}$ \\
\hline Nodule size & $-0.03 ; 0.777$ & $0.05 ; 0.653$ & $0.1 ; 0.384$ & $-0.04 ; 0.973$ \\
\hline Serum VEGF & & $0.47 ; 0.001^{*}$ & $-0.17 ; 0.131$ & $-0.04 ; 0.696$ \\
\hline VEGF inside nodule & & & & $0.02 ; 0.874$ \\
\hline Serum VEGFR-1 & & $-0.02 ; 0.845$ & & $0.31 ; 0.006^{*}$ \\
\hline
\end{tabular}

VEGF=Vascular endothelial growth factor, BMl=Body mass index

In our study, the mean sVEGFR-1 level was significantly higher in men when compared to women $(P=0.045)$. In contrast to our results, Kajdaniuk et al. did not find any differences between men and women. ${ }^{[29]}$

Increased levels of VEGF and VEGFR-1 have been identified in adults and children with papillary and follicular tumors. ${ }^{[5,16,26]}$ The size of anaplastic thyroid tumors has been shown to reduce the inhibition of VEGF. ${ }^{[14]}$ However, in our study, there were no differences between sVEGF, nVEGF, sVEGFR, and nVEGFR levels between benign and suspicious or malignant ultrasonographic features. In addition, according to FNA cytology, there were no significant differences in sVEGF, sVEGFR-1, nVEGF, or nVEGFR levels between benign cytology and malignant or suspicious cytology. This may be due to a small number of patients in the latter two groups.

Zhao et al. reported that the plasma level of VEGF correlated with age. The level in the 40 years and older group was significantly higher than that in the 40 years and younger age group. ${ }^{[26]}$ However, in our study, there was no significant difference between sVEGF, nVEGFR-1, sVEGFR-1, and nVEGFR-1 levels $(P>0.05)$ when patients were grouped according to age as younger than 45 years and older than 45 years.

nVEGFR-1 was significantly higher in normal weight patients compared to obese patients $(P=0.02)$. In contrast to our result, Oranskiy et al. found that the VEGF level was higher in obese or overweight patients compared to normal patients. ${ }^{[30]}$

\section{Conclusions}

In our study, we showed a relationship of sVEGF, nVEGF, sVEGFR-1, and nVEGFR-1 levels with age, gender, BMI, and hyperthyroidism. The number of patients with malignant or suspicious lesions was very small in our study, which is a limitation. Studies that have a greater number of patients are required for further evaluation.
Financial support and sponsorship

Nil.

\section{Conflicts of interest}

There are no conflicts of interest.

\section{References}

1. American Thyroid Association (ATA) Guidelines Taskforce on Thyroid Nodules and Differentiated Thyroid Cancer, Cooper DS, Doherty GM, Haugen BR, Kloos RT, Lee SL, et al. Revised American Thyroid Association management guidelines for patients with thyroid nodules and differentiated thyroid cancer. Thyroid 2009;19:1167-214.

2. Mehanna HM, Jain A, Morton RP, Watkinson J, Shaha A. Investigating the thyroid nodule. BMJ 2009;338:b733.

3. Jin J, McHenry CR. Thyroid incidentaloma. Best Pract Res Clin Endocrinol Metab 2012;26:83-96.

4. Shao YY, Wang L, Ballock RT. Thyroid hormone and the growth plate. Rev Endocr Metab Disord 2006;7:265-71.

5. Fellmer PT, Sato K, Tanaka R, Okamoto T, Kato Y, Kobayashi M, et al. Vascular endothelial growth factor-C gene expression in papillary and follicular thyroid carcinomas. Surgery 1999;126:1056-61.

6. Bikfalvi A. Recent developments in the inhibition of angiogenesis: Examples from studies on platelet factor-4 and the VEGF/VEGFR system. Biochem Pharmacol 2004;68:1017-21.

7. Yamaguchi R, Yano H, Iemura A, Ogasawara S, Haramaki M, Kojiro M, et al. Expression of vascular endothelial growth factor in human hepatocellular carcinoma. Hepatology 1998;28:68-77.

8. Zachary I, Gliki G. Signaling transduction mechanisms mediating biological actions of the vascular endothelial growth factor family. Cardiovasc Res 2001;49:568-81.

9. Clauss M. Molecular biology of the VEGF and the VEGF receptor family. Semin Thromb Hemost 2000;26:561-9.

10. Folkman J. Role of angiogenesis in tumor growth and metastasis. Semin Oncol 2002;29:15-8.

11. Sephel GC, Kennedy R, Kudravi S. Expression of capillary basement membrane components during sequential phases of wound angiogenesis. Matrix Biol 1996;15:263-79.

12. Shweiki D, Itin A, Soffer D, Keshet E. Vascular endothelial growth factor induced by hypoxia may mediate hypoxia-initiated angiogenesis. Nature 1992;359:843-5.

13. Belletti B, Ferraro P, Arra C, Baldassarre G, Bruni P, Staibano S, et al. Modulation of in vivo growth of thyroid tumor-derived cell lines by sense and antisense vascular endothelial growth factor gene. Oncogene 1999;18:4860-9.

14. Soh EY, Duh QY, Sobhi SA, Young DM, Epstein HD, Wong MG, et al. Vascular endothelial growth factor expression is higher in differentiated thyroid cancer than in normal or benign thyroid. 
J Clin Endocrinol Metab 1997;82:3741-7.

15. Klein M, Picard E, Vignaud JM, Marie B, Bresler L, Toussaint B, et al. Vascular endothelial growth factor gene and protein: Strong expression in thyroiditis and thyroid carcinoma. J Endocrinol 1999;161:41-9.

16. Hofmann A, Gessl A, Girschele F, Novotny C, Kienast O, Staudenherz A, et al. Vascular endothelial growth factor in thyroid cyst fluids. Wien Klin Wochenschr 2007;119:248-53.

17. Tuttle RM, Fleisher M, Francis GL, Robbins RJ. Serum vascular endothelial growth factor levels are elevated in metastatic differentiated thyroid cancer but not increased by short-term TSH stimulation. J Clin Endocrinol Metab 2002;87:1737-42.

18. Sato K, Miyakawa M, Onoda N, Demura H, Yamashita T, Miura M, et al. Increased concentration of vascular endothelial growth factor/vascular permeability factor in cyst fluid of enlarging and recurrent thyroid nodules. J Clin Endocrinol Metab 1997;82:1968-73.

19. Jebreel A, England J, Bedford K, Murphy J, Karsai L, Atkin S. Vascular endothelial growth factor (VEGF), VEGF receptors expression and microvascular density in benign and malignant thyroid diseases. Int J Exp Pathol 2007;88:271-7.

20. Iitaka M, Miura S, Yamanaka K, Kawasaki S, Kitahama S, Kawakami $Y$, et al. Increased serum vascular endothelial growth factor levels and intrathyroidal vascular area in patients with Graves' disease and Hashimoto's thyroiditis. J Clin Endocrinol Metab 1998;83:3908-12.

21. Akslen LA, Livolsi VA. Increased angiogenesis in papillary thyroid carcinoma but lack of prognostic importance. Hum Pathol 2000;31:439-42.

22. Viglietto G, Romano A, Manzo G, Chiappetta G, Paoletti I, Califano $\mathrm{D}$, et al. Upregulation of the angiogenic factors plGF, VEGF and their receptors (Flt-1, flk-1/KDR) by TSH in cultured thyrocytes and in the thyroid gland of thiouracil-fed rats suggest a TSH-dependent paracrine mechanism for goiter hypervascularization. Oncogene 1997;15:2687-98.
23. Sato K, Yamazaki K, Shizume K, Kanaji Y, Obara T, Ohsumi K, et al. Stimulation by thyroid-stimulating hormone and Graves' immunoglobulin $G$ of vascular endothelial growth factor mRNA expression in human thyroid follicles in vitro and flt mRNA expression in the rat thyroid in vivo. J Clin Invest 1995;96:1295-302.

24. Shushanov S, Bronstein M, Adélaïde J, Jussila L, Tchipysheva T, Jacquemier $\mathrm{J}$, et al. VEGFc and VEGFR3 expression in human thyroid pathologies. Int J Cancer 2000;86:47-52.

25. Hataya Y, Akamizu T, Kanamoto N, Moriyama K, Shimatsu A, Nakao K, et al. A case of subclinical hypothyroidism developing marked pleural effusions and peripheral edema with elevated vascular endothelial growth factor. Endocr J 2007;54:577-84.

26. Zhao X, Wang G, You J. Measurement and correlation analysis of plasma VEGF level in the patients of hyperthyroidism. Sheng Wu Yi Xue Gong Cheng Xue Za Zhi 2013;30:365-7.

27. Figueroa-Vega N, Sanz-Cameno P, Moreno-Otero R, Sánchez-Madrid F, González-Amaro R, Marazuela M, et al. Serum levels of angiogenic molecules in autoimmune thyroid diseases and their correlation with laboratory and clinical features. J Clin Endocrinol Metab 2009;94:1145-53.

28. Bunone G, Vigneri P, Mariani L, Butó S, Collini P, Pilotti S, et al. Expression of angiogenesis stimulators and inhibitors in human thyroid tumors and correlation with clinical pathological features. Am J Pathol 1999;155:1967-76.

29. Kajdaniuk D, Marek B, Niedziołka-Zielonka D, Foltyn W, Nowak M, Siemińska L, et al. Transforming growth factor $\beta 1$ (TGF $\beta 1$ ) and vascular endothelial growth factor (VEGF) in the blood of healthy people and patients with Graves' orbitopathy - A new mechanism of glucocorticoids action? Endokrynol Pol 2014;65:348-56.

30. Oranskiy SP, Yeliseyeva LN, Tsanaeva AV, Zaytseva NV. Body composition and serum levels of adiponectin, vascular endothelial growth factor, and interleukin-6 in patients with rheumatoid arthritis. Croat Med J 2012;53:350-6. 